\title{
Predictors of Immunosuppressive Regulatory $T$ Lymphocytes in Healthy Women
}

\author{
Shalaka S. Hampras, ${ }^{1}$ Mary Nesline, ${ }^{1}$ Paul K. Wallace, ${ }^{2}$ Kunle Odunsi, ${ }^{3}$ Nicholas Furlani, ${ }^{4}$ \\ Warren Davis, ${ }^{1}$ and Kirsten B. Moysich ${ }^{1}$
}

${ }^{1}$ Department of Cancer Prevention and Control, Roswell Park Cancer Institute, Buffalo, NY 14263, USA

${ }^{2}$ Department of Flow and Image Cytometry, Roswell Park Cancer Institute, Buffalo, NY 14263, USA

${ }^{3}$ Department of Gynecology, Roswell Park Cancer Institute, Buffalo, NY 14263, USA

${ }^{4}$ School of Medicine, Stony Brook University, Stony Brook, NY 11790, USA

Correspondence should be addressed to Kirsten B. Moysich, kirsten.moysich@roswellpark.org

Received 24 April 2012; Accepted 12 July 2012

Academic Editor: L. A. Liotta

Copyright (C 2012 Shalaka S. Hampras et al. This is an open access article distributed under the Creative Commons Attribution License, which permits unrestricted use, distribution, and reproduction in any medium, provided the original work is properly cited.

Immunosuppressive regulatory $\mathrm{T}$ (Treg) cells play an important role in antitumor immunity, self-tolerance, transplantation tolerance, and attenuation of allergic response. Higher proportion of Treg cells has been observed in peripheral blood of cancer cases compared to controls. Little is known about potential epidemiological predictors of Treg cell levels in healthy individuals. We conducted a cross-sectional study including 75 healthy women, between 20 and 80 years of age, who participated in the Data Bank and BioRepository (DBBR) program at Roswell Park Cancer Institute (RPCI), Buffalo, NY, USA. Peripheral blood levels of $\mathrm{CD}^{+} \mathrm{CD} 25^{+} \mathrm{FOXP}^{+}$Treg cells were measured using flow cytometric analysis. A range of risk factors was evaluated using Wilcoxon Rank-Sum test, Kruskal-Wallis test, and linear regression. Age, smoking, medications for treatment of osteoporosis, postmenopausal status, body mass index (BMI), and hormone replacement therapy (HRT) were found to be significant positive predictors of Treg cell levels in peripheral blood $(P \leq 0.05)$. Higher education, exercise, age at first birth, oral contraceptives, and use of Ibuprofen were found be significant $(P<0.05)$ negative predictors of Treg levels. Thus, various epidemiological risk factors might explain interindividual variation in immune response to pathological conditions, including cancer.

\section{Introduction}

There is a growing body of evidence implicating regulatory $\mathrm{T}$ (Treg) cells in the etiology and prognosis of many cancers and autoimmune diseases [1-5] as well as in the prevention of graft versus host disease [6,7]. Treg cells have also been found to suppress reactivity against paternal alloantigens during pregnancy, thus regulating antifetal immune reactions [8]. Treg cells constitute 5-10\% [9] of peripheral $\mathrm{CD} 4^{+} \mathrm{T}$ cells and majority of them are produced in the thymus [10]. Treg cells first attracted attention for their role in maintaining immune tolerance and in the development of severe autoimmune disorders. In a seminal study, Asona et al. demonstrated that while thymectomized mice developed autoimmune disorders, restoration of Treg cells from syngeneic nonthymectomized mice suppressed autoimmune disorders [11]. The immunosuppressive role of Treg cells was later confirmed in several other studies [1214].

High Treg cell levels have been previously reported in the peripheral blood of patients with pancreatic [15], ovarian [16], head and neck [17], prostate [18], lung $[19,20]$, gastric [21], colorectal [21], esophageal, and liver cancers [21], compared to healthy individuals. Treg cells from cancer patients have been found to express similar surface molecules and cytokine activity as those expressed by Treg cells in healthy individuals [15]. Further, Treg cells from peripheral blood of cancer patients suppressed proliferation and function of natural $\mathrm{T}$ cells [15]. These findings suggest that the increased Treg cells in cancer patients are functionally similar to the Treg cells in healthy individuals and suppress normal immune responses against 
tumors [15]. Although, higher Treg cell levels have been observed in the peripheral blood of cancer cases compared to controls, there is scarcity of literature on the factors that affect the levels of Treg cells in healthy individuals. We examined the association of several epidemiological factors including demographic and lifestyle factors, diet, medication use, and reproductive factors, with Treg cell levels in peripheral blood in a well-defined cohort of 75 healthy women.

\section{Materials and Methods}

Participants in this study were women who consented to participate in the Data Bank and BioRepository (DBBR) program, a shared Core Research Resource at Roswell Park Cancer Institute in Buffalo, NY, USA [22] and self-reported being cancer-free at the time of informed consent. The DBBR is a state-of-the-art blood collection, processing, and banking laboratory which procures bio specimens from Roswell Park patients and nonpatients as healthy controls and collects extensive sample and clinical annotation data, as well as epidemiological survey information. Newly diagnosed cancer patients are asked to contribute specimens and data to the DBBR prior to treatment, and non-patients (family members and friends of patients and community members) with no personal history of cancer are also asked to participate in the DBBR as controls. All participants provide broad, tiered, face-to-face informed consent to donate at least one blood sample and to complete a self-administered in-depth epidemiologic questionnaire, which includes a Food Frequency Questionnaire, information on reproductive history, family history of cancer, dietary supplement use, comorbidities, prescription and nonprescription medication use, smoking, alcohol consumption, lifetime physical activity, height and weight from young adulthood to present, and demographic factors. Specimens and data are collected with protected health information (PHI) and subsequently deidentified through a certified honest broker prior to distribution to scientists with hypothesis-driven IRB-approved research studies.

For this study, peripheral blood samples were procured through the DBBR resource by certified phlebotomists from 107 women who verbally reported having no current or prior history of cancer at the time of consent between January 2008 and April 2009. The blood samples were collected and immediately sent via pneumatic tube from the DBBR laboratory to the Flow and Image Cytometry resource at RPCI, where it was initially stored at $-80^{\circ} \mathrm{C}$. Cells were thawed, washed, and checked for viability using Fixable Live Dead Violet (Life technologies, Grand Island, NY, USA). The cells were stained with FOXP3 Ax488 (clone 206D, Bio Legend, San Diego, CA, USA, CD127 PE (clone R34.34, Beckman Coulter, Miami, FL, USA), CD4 PerCP (clone OKT-4, Bio Legend), CD3 PECy7 (clone SK7 8-11, BD Bioscience San Jose, CA, USA), and CD25 APC (clone 2A3, $\mathrm{BD}$ Bioscience), as previously described [23]. For each sample an FMO (fluorescence minus one) control, substituting an isotype control (IgG1k Ax488, Bio Legend) for FOXP3, was used to establish the boundaries for FOXP3 negativity. Cytofluorometric analysis was performed using a FACSCanto II (BD BioSciences) flow cytometer equipped with air cooled 405, 488, and $633 \mathrm{~nm}$ lasers. Forward scatter, side scatter, and five fluorescent parameters were collected with a threshold set on forward scatter to eliminate debris from list mode data. For this study, $\mathrm{CD} 3^{+} \mathrm{CD} 4^{+} \mathrm{CD} 25^{+} \mathrm{FOXP}^{+}$ was used as the principle definition of Treg cells, and results are expressed as percentage of total $\mathrm{CD}^{+}$cells. Foxp3 is considered to be highly specific marker for Treg cells $[24,25]$.

At the end of one year of follow-up time (April 2010), 82 $(76 \%)$ of sample donors had returned their epidemiological questionnaires to the DBBR for data processing. Following standard operating procedures, each questionnaire was reviewed by both a data manager and a trained, dedicated research associate who recontact participants via telephone to clarify discrepancies prior to scanning the data for storage and subsequent distribution alongside biospecimens. Women with missing data on some of the important variables of interest in this study, such as education, smoking, exercise, age at first birth, use of oral contraceptives, history of HRT, and use of Ibuprofen were excluded from analyses. Thus, data for a total of 75 women was available for analyses.

2.1. Statistical Analysis. Since the distribution of Treg cells was not normal within comparison groups of epidemiological predictors, mean percentages of Treg cells were compared using Wilcoxon Rank-Sum test and Kruskal-Wallis test as appropriate. Univariate linear regression was used to test the association of demographics, lifestyle, medication use, diet, and reproductive factors with the levels of Treg cells. Dummy variables were created as appropriate for categorical predictors. All analyses were conducted using SAS 9.3.1.

\section{Results}

Table 1 displays the descriptive characteristics of 75 healthy women in the study. The majority of study population were Caucasian, had greater than high school level of education, and were postmenopausal (Table 1). Mean percentage (\% of $\mathrm{CD}^{+}$) of Treg level was $2.64 \%$ (standard deviation = 1.33). Since Treg cell levels were expressed as proportion of total $\mathrm{CD}^{+} \mathrm{T}$ cells as opposed to that of $\mathrm{CD}^{+} \mathrm{T}$ cells, these levels are lower than those reported by other studies $[15,26]$. Women with higher BMI, lack of exercise, smoking, younger age at first birth, postmenopausal status, and HRT had significantly higher mean percentage of Treg cells than the respective comparison groups. As shown in Table 2, age, smoking, exposure to medications for treatment of osteoporosis, post-menopausal status, BMI, and history of hormone replacement therapy (HRT) were found to be significant positive predictors of Treg cell levels $(P \leq$ 0.05 ). On the other hand, education, exercise (3 or more days/week), >24 years of age at first birth, and use of oral contraceptives or Ibuprofen were found be significant negative predictors of Treg cell levels. When compared with nulliparous women, neither category of age at first birth 
TABle 1: Mean regulatory T-cell (Treg) levels across categories of demographic, lifestyle, diet, medication use, and reproductive characteristics of 75 healthy women at Roswell Park Cancer Institute, Buffalo, NY, USA, 2008-2009.

\begin{tabular}{|c|c|c|c|}
\hline Variable & Sample $N(\%)$ or mean (STD) & Treg levels mean (STD) & $P$ value \\
\hline \multicolumn{4}{|l|}{ Demographic characteristics } \\
\hline a Age (Years) & $57.56(11.93)$ & & \\
\hline${ }^{\mathrm{b}}$ Age $\leq 60$ years & $41(54.67)$ & $2.39(1.20)$ & \\
\hline Age $>60$ years & $34(45.33)$ & $2.95(1.43)$ & $* 0.10$ \\
\hline \multicolumn{4}{|l|}{${ }^{\mathrm{b}}$ Race } \\
\hline White & $73(97.33)$ & & \\
\hline Black & $2(2.67)$ & & \\
\hline${ }^{\mathrm{a} B o d y}$ mass index (BMI) $\left(\mathrm{kg} / \mathrm{m}^{2}\right)$ & $28.44(6.06)$ & & \\
\hline \multicolumn{4}{|l|}{${ }^{\mathrm{b}} \mathrm{BMI}\left(\mathrm{kg} / \mathrm{mm}^{2}\right)$} \\
\hline $18-24$ & $26(35.14)$ & $2.22(0.96)$ & $* * 0.02$ \\
\hline $25-29$ & $21(28.38)$ & $3.33(1.56)$ & \\
\hline 30 or more & $27(36.49)$ & $2.44(1.24)$ & \\
\hline \multicolumn{4}{|l|}{ bEducation } \\
\hline Less than or equal to high school & $19(25.33)$ & $3.37(1.20)$ & ${ }^{*} \mathbf{0 . 0 0 3}$ \\
\hline Greater than high school & $56(74.67)$ & $2.40(1.28)$ & \\
\hline \multicolumn{4}{|l|}{${ }^{\mathrm{b}}$ Health insurance } \\
\hline Medicaid/Medicare & $10(16.13)$ & $3.26(1.72)$ & $* 0.21$ \\
\hline Employer-sponsored & $52(83.87)$ & $2.44(1.06)$ & \\
\hline \multicolumn{4}{|l|}{${ }^{\mathrm{b}}$ Marital status } \\
\hline Married/living as married & $52(69.33)$ & $2.60(1.35)$ & $* * 0.51$ \\
\hline Widowed/separated/divorced & $17(22.67)$ & $2.88(1.23)$ & \\
\hline Single & $6(8.00)$ & $2.35(1.55)$ & \\
\hline \multicolumn{4}{|l|}{${ }^{\mathrm{b}}$ Household income (per annum) } \\
\hline$\leq \$ 24,999$ & $11(16.42)$ & $3.06(1.56)$ & ${ }^{* *} 0.47$ \\
\hline$\$ 25,000$ to $\$ 74,499$ & $44(65.67)$ & $2.51(1.20)$ & \\
\hline$\$ 75,000+$ & $12(17.91)$ & $2.41(1.02)$ & \\
\hline \multicolumn{4}{|l|}{ Lifestyle } \\
\hline \multicolumn{4}{|l|}{ bSmoking } \\
\hline Never & $38(50.67)$ & $2.29(1.24)$ & ${ }^{*} 0.01$ \\
\hline Ever & $37(49.33)$ & $3.00(1.33)$ & \\
\hline aAlcohol (frequency per month) & $12.30(18.91)$ & & \\
\hline \multicolumn{4}{|l|}{${ }^{\mathrm{b}}$ Exercise } \\
\hline None & $24(32.00)$ & $3.04(1.36)$ & $* * 0.04$ \\
\hline 1-2 days per week & $25(33.33)$ & $2.82(1.49)$ & \\
\hline 3 or more days per week & $26(34.67)$ & $2.10(0.95)$ & \\
\hline \multicolumn{4}{|l|}{ Reproductive characteristics } \\
\hline \multicolumn{4}{|l|}{${ }^{\mathrm{b}}$ Menopausal status } \\
\hline Premenopausal & $28(37.33)$ & $2.25(0.95)$ & $* 0.10$ \\
\hline Postmenopausal & $47(62.67)$ & $2.88(1.47)$ & \\
\hline \multicolumn{4}{|l|}{ bage at first birth } \\
\hline$\leq 24$ years & $37(59.68)$ & $2.90(1.19)$ & \\
\hline$>24$ years & $25(40.32)$ & $2.12(1.08)$ & ${ }^{*} 0.01$ \\
\hline \multicolumn{4}{|l|}{${ }^{\mathrm{b}}$ Age at menarche } \\
\hline 13 or younger & $54(73.97)$ & $2.75(1.43)$ & \\
\hline 14 or greater & $19(26.03)$ & $2.35(1.05)$ & $* 0.35$ \\
\hline \multicolumn{4}{|l|}{${ }^{b}$ Ever used oral contraceptives } \\
\hline No & $23(30.67)$ & $3.13(1.72)$ & $* 0.16$ \\
\hline Yes & $52(69.33)$ & $2.43(1.06)$ & \\
\hline \multicolumn{4}{|l|}{${ }^{\mathrm{b}}$ Ever used HRT } \\
\hline No & $59(78.67)$ & $2.46(1.18)$ & ${ }^{*} 0.05$ \\
\hline Yes & $16(21.33)$ & $3.31(1.64)$ & \\
\hline
\end{tabular}


TABle 1: Continued.

\begin{tabular}{|c|c|c|c|}
\hline Variable & Sample $N(\%)$ or mean (STD) & Treg levels mean (STD) & $P$ value \\
\hline \multicolumn{4}{|l|}{${ }^{\mathrm{b}}$ Ever given birth } \\
\hline No & $13(17.33)$ & $2.93(1.84)$ & \multirow[t]{2}{*}{$* 0.61$} \\
\hline Yes & $62(82.67)$ & $2.58(1.20)$ & \\
\hline \multicolumn{4}{|l|}{${ }^{\mathrm{b}}$ Ever breast fed } \\
\hline No & $32(51.61)$ & $2.82(1.25)$ & \multirow[t]{2}{*}{$* 0.18$} \\
\hline Yes & $30(48.39)$ & $2.32(1.12)$ & \\
\hline \multicolumn{4}{|l|}{${ }^{\mathrm{b}}$ Family history } \\
\hline No & $64(85.33)$ & $2.59(1.24)$ & \multirow[t]{2}{*}{$* 0.49$} \\
\hline Yes & $11(14.67)$ & $2.92(1.78)$ & \\
\hline \multicolumn{4}{|l|}{${ }^{\mathrm{b}, \mathrm{d}}$ Multivitamins } \\
\hline No & $18(28.57)$ & $2.89(1.65)$ & \multirow[t]{2}{*}{$* 0.76$} \\
\hline Yes & $45(71.43)$ & $2.64(1.27)$ & \\
\hline \multicolumn{4}{|l|}{ b'Ibuprofen } \\
\hline Never & $21(28.0)$ & $3.23(1.53)$ & \multirow[b]{2}{*}{$* 0.03$} \\
\hline Ever & $54(72.0)$ & $2.41(1.18)$ & \\
\hline \multicolumn{4}{|l|}{${ }^{\mathrm{b}}$ Osteoporosis medication } \\
\hline Never & $62(82.67)$ & $2.44(1.11)$ & \multirow[t]{2}{*}{${ }^{*} 0.03$} \\
\hline Ever & $13(17.33)$ & $3.61(1.83)$ & \\
\hline \multicolumn{4}{|l|}{${ }^{\mathrm{b}}$ Acetaminophen use } \\
\hline Never & $12(16.0)$ & $3.10(1.78)$ & \multirow[t]{2}{*}{$* 0.43$} \\
\hline Ever & $63(84.0)$ & $2.55(1.22)$ & \\
\hline \multicolumn{4}{|l|}{${ }^{\mathrm{b}}$ Aspirin use } \\
\hline Never & $17(22.67)$ & $2.19(1.06)$ & \multirow[b]{2}{*}{$* 0.09$} \\
\hline Ever & $58(77.33)$ & $2.77(1.37)$ & \\
\hline \multicolumn{4}{|l|}{${ }^{\mathrm{b}}$ Prednisone use } \\
\hline Never & $60(81.08)$ & $2.71(1.39)$ & \multirow[t]{2}{*}{$* 0.85$} \\
\hline Ever & $14(18.92)$ & $2.43(1.07)$ & \\
\hline \multicolumn{4}{|l|}{${ }^{\mathrm{d}}$ Diet } \\
\hline${ }^{a}$ Vegetables & $8.92(8.48)$ & & \\
\hline \multicolumn{4}{|l|}{${ }^{\mathrm{b}}$ Vegetables } \\
\hline$\leq 7$ times per week & $57(76.0)$ & $2.78(1.38)$ & \multirow[t]{2}{*}{${ }^{*} 0.08$} \\
\hline$>7$ times per week & $18(24.0)$ & $2.2(1.05)$ & \\
\hline${ }^{\mathrm{a}}$ Fruits & $9.11(9.81)$ & & \\
\hline \multicolumn{4}{|l|}{${ }^{\mathrm{b}}$ Fruits } \\
\hline$\leq 5.5$ times per week & $40(53.33)$ & $2.75(1.31)$ & \multirow[t]{2}{*}{$* 0.30$} \\
\hline$>5.5$ times per week & $35(46.67)$ & $2.52(1.35)$ & \\
\hline${ }^{\mathrm{a}}$ Treg $\left(\%\right.$ of $\left.\mathrm{CD}^{+}{ }^{+}\right)$ & $2.64(1.33)$ & & \\
\hline
\end{tabular}

Abbreviation: HRT: hormone replacement therapy.

$P$ value determined using *Wilcoxon Rank-Sum test and ${ }^{* *}$ Kruskal-Wallis test of one-way analysis of variance as appropriate, ${ }^{\text {a }}$ Mean (standard deviation), ${ }^{\mathrm{b}} N(\%),{ }^{\mathrm{c}}$ current intake of vitamin supplements, ${ }^{\mathrm{d}}$ dietary intake of fruits, and vegetables defined as frequency per week. Exercise was defined as days per week of at least 20 min of exercise currently.

was found to be significant (results not shown). $5 \%$ to $12 \%$ of variation in Treg levels was explained by these variables (Table 2).

\section{Discussion}

In this first cross-sectional study of epidemiological predictors of Treg cells, we identified several factors that are positively or negatively associated with these immunosuppressive cells.
A distinct subset of $\mathrm{CD}^{+}, \mathrm{CD} 25^{+} \mathrm{T}$ lymphocytes expressing FOXP3 (Treg cells) has been found to play an important role in dampening host immune response and in preventing autoimmunity [10, 24, 27-29]. Increased proportion of immunosuppressive Treg cells has been observed in cancer patients indicating the role of Treg cells in suppression of anti-tumor immunity $[15,26]$. Treg cells have been implicated in several diseases including type 1 diabetes [1], multiple sclerosis $[2,3]$, systemic lupus erythematosis [4], and rheumatoid arthritis [5]. Although a number of 
TABLE 2: Linear regression analyses of epidemiological predictors of regulatory T-cell (Treg) levels among 75 healthy women at Roswell Park Cancer Institute, Buffalo, NY, USA, 2008-2009.

\begin{tabular}{|c|c|c|c|}
\hline Variable & $\beta$ & $P$ value & $R^{2}$ \\
\hline \multicolumn{4}{|l|}{ Demographic variables } \\
\hline${ }^{1}$ Age (years) & 0.02 & 0.05 & 0.05 \\
\hline${ }^{2}$ Education & -0.97 & 0.005 & 0.10 \\
\hline${ }^{1} \mathrm{BMI}\left(\mathrm{kg} / \mathrm{mm}^{2}\right)$ & 0.01 & 0.78 & 0.001 \\
\hline \multicolumn{4}{|l|}{ BMI $\left(\mathrm{kg} / \mathrm{mm}^{2}\right)$} \\
\hline $18-24$ & Reference & & \\
\hline $25-29$ & 1.11 & 0.004 & 0.12 \\
\hline 30 or more & 0.22 & 0.52 & \\
\hline \multicolumn{4}{|l|}{ Lifestyle factors } \\
\hline Smoking & 0.71 & 0.02 & 0.07 \\
\hline${ }^{3}$ Alcohol intake & 0.01 & 0.19 & 0.02 \\
\hline \multicolumn{4}{|l|}{ Exercise } \\
\hline None & Reference & & 0.09 \\
\hline 1-2 days/week & -0.22 & 0.55 & \\
\hline 3 or more days/week & -0.94 & 0.01 & \\
\hline \multicolumn{4}{|l|}{ Reproductive factors } \\
\hline Menopausal status & 0.63 & 0.04 & 0.05 \\
\hline${ }^{4}$ Age at first birth & -0.78 & 0.01 & 0.10 \\
\hline${ }^{5}$ Age at menarche & -0.41 & 0.26 & 0.02 \\
\hline Oral contraceptives & -0.70 & 0.03 & 0.06 \\
\hline HRT & 0.84 & 0.02 & 0.07 \\
\hline Parity & -0.35 & 0.39 & 0.01 \\
\hline Breast feeding & -0.50 & 0.10 & 0.04 \\
\hline Family history & 0.32 & 0.46 & 0.01 \\
\hline \multicolumn{4}{|l|}{ Medications } \\
\hline${ }^{6}$ Multivitamins & -0.25 & 0.52 & 0.01 \\
\hline${ }^{7}$ Ibuprofen & -0.82 & 0.01 & 0.08 \\
\hline${ }^{7}$ Osteoporosis medication & 1.18 & 0.003 & 0.11 \\
\hline${ }^{7}$ Acetaminophen & -0.54 & 0.19 & 0.02 \\
\hline${ }^{7}$ Aspirin & 0.58 & 0.11 & 0.03 \\
\hline${ }^{7}$ Prednisone & -0.27 & 0.49 & 0.01 \\
\hline \multicolumn{4}{|l|}{${ }^{8}$ Diet } \\
\hline Vegetable & -0.02 & 0.19 & 0.02 \\
\hline Fruits & -0.02 & 0.28 & 0.02 \\
\hline
\end{tabular}

HRT: hormone replacement therapy.

${ }^{1}$ Continuous variable.

${ }^{2}$ Education level categorized as less than or equal to high school and more than high school.

${ }^{3}$ Frequency of drinking beer/wine/liquor per month in the past one year.

${ }^{4} \mathrm{Age}$ at first birth categorized as $\leq 24$ years (reference) and $>24$ years.

${ }^{5}$ Age at menarche categorized as $\leq 13$ years and $\geq 14$ years.

${ }^{6}$ Current intake of multivitamins categorized as none $=0$ and $1=$ yes.

${ }^{7}$ Intake in the past: $0=$ Never, $1=$ yes, occasionally or at least once a week for one full year.

${ }^{8}$ Frequency per week.

Exercise was defined as days per week of at least 20 min of exercise currently.

surface markers expressed by Treg cells is being continually discovered to define this unique subset of $\mathrm{T}$ cells, the expression of forkhead box P3 (FOXP3) has been found to be specific for naturally occurring Treg cells [24]. Hence, in this study, $\mathrm{CD}^{+}{ }^{+} \mathrm{CD} 4^{+} \mathrm{CD} 25^{+} \mathrm{FOXP}^{+}$phenotype was used as the principal definition of Treg cells. We attempted, for the first time, to evaluate various epidemiological factors that may predict the levels of Treg cells in a cohort of 75 healthy women.

A wide range of demographic, lifestyle, medication use, dietary, and reproductive factors were evaluated in association with mean Treg cell levels. Age was significantly and positively associated with Treg levels $(P=0.05)$. This observation is consistent with previous literature [30]. It has been suggested that increasing Treg levels in the elderly might be responsible for decreased immunity with age [30]. Age explained 5\% variation in Treg levels in our population (Table 2). Smoking, postmenopausal status, exposure to drugs such as HRT, osteoporosis medications, and lower education levels were found to be associated with significantly $(P<0.05)$ higher levels of Treg cells (Table 2). Our finding on smoking and Treg cells is consistent with previous literature [31]. Smoking exposure in murine models has been found to significantly upregulate Treg levels [32], reduce helper/suppressor T-cell ratio [33], and induce immunosuppressive cytokines such as IL-10 [34]. Upregulation of Treg levels among smokers has been suggested to be a protective mechanism against the inflammatory response elicited by smoking [31]. If smoking-induced inflammatory response is associated with induction of Treg cells, then it follows that anti-inflammatory drug exposure should be associated with lower Treg levels. We found that women who used nonsteroidal anti-inflammatory (NSAID) drugs such as Ibuprofen had significantly lower levels of Treg cells compared to who women who did not use these drugs (Table 1). In vitro studies have found that drugs such as Cox2 inhibitors reduce Foxp3 expression on Treg cells and reverse the suppressive function of Treg cells [35]. On the other hand, anti-inflammatory drugs such as Ketoprofen have been found to up regulate Treg cells in murine model [36]. We did not find any significant difference in Treg cell levels between women who ever used other NSAID drugs such as Cox2 inhibitors, Naproxen, and Acetyl Salicylic Acid compared to women who did not use these drugs (results not shown). Further research is required to better understand the potential role of NSAIDs in modifying Treg cell levels or function.

We found that women who had a history of HRT had significantly higher levels of Treg cells compared to those who were not exposed to HRT. Exposure to high estrogen through HRT might be the underlying mechanism explaining our findings. Indeed, it has been suggested that hormonal factors such as estrogen up regulate Treg cells [37, 38]. Expansion of Treg cells during the preovulatory phase of menstrual cycle, when estrogen levels are higher, has been described previously [37]. Among other drug exposures, occasional or regular use of any medication for treatment of osteoporosis was found to be a positive predictor of Treg levels (Table 2). We do not have information on the specific drugs that these women were exposed to, thus limiting the interpretation of this finding. Among other reproductive variables, older age ( $>24$ years) at first birth was associated with lower Treg levels. Older women in this sample were significantly $(P=0.02)$ more likely to have used oral contraceptives compared to 
younger women. Thus, the finding associated with age at first birth is likely to be confounded by the use of oral contraceptives.

Obesity has been found to be associated with higher levels of $\mathrm{CD}^{+} \mathrm{T}$ lymphocytes [39] and reduced levels of Treg cells [40]. Leptin hormone secreted from adipose tissue suppresses the proliferation of Treg cells [41] (reviewed by [42]). In contrast, we found significantly higher levels of Treg cells in women with a BMI between 25 and $29 \mathrm{~kg} / \mathrm{mm}^{2}$ (mean Treg $=3.33 \%$ ) compared to women with a BMI between 18 and $24 \mathrm{~kg} / \mathrm{mm}^{2}$ (mean Treg $=2.22 \%$ ). When treated as a continuous marker, BMI did not significantly predict the levels of Treg cells (Table 2). This could be due to nonlinear association of BMI with Treg levels. Indeed, when analyzed as a categorical predictor, higher BMI was found to be a significant predictor of Treg cell levels.

Education was also found to be a significant predictor of Treg levels (Table 2). This is an interesting and intriguing finding. Education is often used as proxy for socioeconomic status and affects an individual's lifestyle [43]. Education, occupation, and income have a complex interplay and are important determinants of health [43]. It is likely that the finding of lower Treg cell levels among women with higher education in our sample is a reflection of the association of lifestyle factors such as smoking, diet, and physical activity. that may be associated with education.

Although we report some interesting predictors of Treg cell levels in healthy women, our findings should be interpreted with caution. Our study population was restricted to women and predominantly included white participants. Further research including both men and women across different races should be conducted. Since the study population included women who accompanied cancer patients, they may not be representative of the general population. As seen in Table 1, the majority of our study population had higher education, higher income, and almost everyone had health insurance. Thus, the external validity of our findings is limited. Our statistically significant findings may not be clinically relevant due to small magnitude of variation in Treg cells associated with each predictor. Due to small sample size, multivariate analyses were not conducted, thus restricting adjustment for confounding variables.

However, the study has several strengths. This is a first, well-designed epidemiological study to evaluate predictors of Treg levels in a cohort of healthy women. Secondly, we evaluated a wide range of factors including demographic, lifestyle, dietary, reproductive factors, and medication use. However, due to lack of more specific data on some of these variables, further comprehensive evaluation was limited. Although the response rate was $76 \%$, there were no significant differences in demographic characteristics between women who did not return the questionnaires and those who did. Mean Treg cell levels were also not significantly different between the two groups. Thus, the results of our study are unlikely to be biased by low response rate. No significant intraindividual variation in Treg cells in healthy controls has been observed in the past [44]. Thus, the lack of difference in Treg concentration between some groups in this study is unlikely to be due to intraindividual variation. The findings of our study should be explored further in a larger sample to provide better insight into epidemiological predictors of Treg cells.

\section{Conclusion}

We found a number of epidemiological variables that significantly predict the levels of Treg cells in healthy women. Modifiable lifestyle factors such as BMI, exercise, use of oral contraceptives, and NSAIDs should be explored further to better understand their role in modifying Treg cell levels in healthy adults.

\section{Acknowledgments}

This work was supported by grants from the Susan G. Komen for the Cure Foundation (BCTR0706811) and the National Cancer Institute (NCI) (P30 CA016056).

\section{References}

[1] S. Lindley, C. M. Dayan, A. Bishop, B. O. Roep, M. Peatman, and T. I. M. Tree, "Defective suppressor function in $\mathrm{CD} 4{ }^{+} \mathrm{CD} 25^{+}$T-cells from patients with type 1 diabetes," Diabetes, vol. 54, no. 1, pp. 92-99, 2005.

[2] J. Huan, N. Culbertson, L. Spencer et al., "Decreased FOXP3 levels in multiple sclerosis patients," Journal of Neuroscience Research, vol. 81, no. 1, pp. 45-52, 2005.

[3] K. Venken, N. Hellings, T. Broekmans, K. Hensen, J. L. Rummens, and P. Stinissen, "Natural naive $\mathrm{CD} 4{ }^{+} \mathrm{CD} 25^{+} \mathrm{CD} 127^{\text {low }}$ regulatory $\mathrm{T}$ cell (Treg) development and function are disturbed in multiple sclerosis patients: recovery of memory Treg homeostasis during disease progression," Journal of Immunology, vol. 180, no. 9, pp. 6411-6420, 2008.

[4] S. C. Lin, K. H. Chen, C. H. Lin, C. C. Kuo, Q. D. Ling, and C. H. Chan, "The quantitative analysis of peripheral blood FOXP3-expressing T cells in systemic lupus erythematosus and rheumatoid arthritis patients," European Journal of Clinical Investigation, vol. 37, no. 12, pp. 987-996, 2007.

[5] C. A. Lawson, A. K. Brown, V. Bejarano et al., "Early rheumatoid arthritis is associated with a deficit in the $\mathrm{CD} 4{ }^{+} \mathrm{CD} 25$ high regulatory $\mathrm{T}$ cell population in peripheral blood," Rheumatology, vol. 45, no. 10, pp. 1210-1217, 2006.

[6] S. N. Ukena, S. Velaga, R. Geffers et al., "Human regulatory T cells in allogeneic stem cell transplantation," Blood, vol. 118, no. 13, pp. e82-e92, 2011.

[7] P. A. Taylor, R. J. Noelle, and B. R. Blazar, "CD4 ${ }^{+} \mathrm{CD} 25^{+}$ immune regulatory cells are required for induction of tolerance to alloantigen via costimulatory blockade," Journal of Experimental Medicine, vol. 193, no. 11, pp. 1311-1317, 2001.

[8] J. Mjösberg, G. Berg, J. Ernerudh, and C. Ekerfelt, "CD4 ${ }^{+}$ $\mathrm{CD} 25^{+}$regulatory $\mathrm{T}$ cells in human pregnancy: development of a Treg-MLC-ELISPOT suppression assay and indications of paternal specific Tregs," Immunology, vol. 120, no. 4, pp. 456466, 2007.

[9] P. A. Antony, C. M. Paulos, M. Ahmadzadeh et al., "Interleukin-2-dependent mechanisms of tolerance and immunity in vivo," Journal of Immunology, vol. 176, no. 9, pp. 5255-5266, 2006.

[10] S. Sakaguchi, "Naturally arising $\mathrm{CD} 4^{+}$regulatory $\mathrm{T}$ cells for immunologic self-tolerance and negative control of immune 
responses," Annual Review of Immunology, vol. 22, pp. 531562, 2004.

[11] M. Asano, M. Toda, N. Sakaguchi, and S. Sakaguchi, "Autoimmune disease as a consequence of developmental abnormality of a T cell subpopulation," Journal of Experimental Medicine, vol. 184, no. 2, pp. 387-396, 1996.

[12] B. Mukherji, A. Guha, N. G. Chakraborty et al., "Clonal analysis of cytotoxic and regulatory $\mathrm{T}$ cell responses against human melanoma," Journal of Experimental Medicine, vol. 169, no. 6, pp. 1961-1976, 1989.

[13] B. Mukherji, A. L. Nashed, A. Guha, and M. T. Ergin, "Regulation of cellular immune response against autologous human melanoma. II. Mechanism of induction and specificity of suppression," Journal of Immunology, vol. 136, no. 5, pp. 1893-1898, 1986.

[14] B. Mukherji, S. A. Wilhelm, A. Guha, and M. T. Ergin, "Regulation of cellular immune response against autologous human melanoma. I. Evidence for cell-mediated suppression of in vitro cytotoxic immune response," Journal of Immunology, vol. 136, no. 5, pp. 1888-1892, 1986.

[15] U. K. Liyanage, T. T. Moore, H. G. Joo et al., "Prevalence of regulatory $\mathrm{T}$ cells is increased in peripheral blood and tumor microenvironment of patients with pancreas or breast adenocarcinoma," Journal of Immunology, vol. 169, no. 5, pp. 2756-2761, 2002.

[16] B. Barnett, I. Kryczek, P. Cheng, W. Zou, and T. J. Curiel, "Regulatory T cells in ovarian cancer: biology and therapeutic potential," American Journal of Reproductive Immunology, vol. 54, no. 6, pp. 369-377, 2005.

[17] K. Chikamatsu, K. Sakakura, T. L. Whiteside, and N. Furuya, "Relationships between regulatory $\mathrm{T}$ cells and $\mathrm{CD} 8^{+}$effector populations in patients with squamous cell carcinoma of the head and neck," Head and Neck, vol. 29, no. 2, pp. 120-127, 2007.

[18] A. M. Miller, K. Lundberg, V. Özenci et al., "CD4 ${ }^{+} \mathrm{CD} 25$ high $\mathrm{T}$ cells are enriched in the tumor and peripheral blood of prostate cancer patients," Journal of Immunology, vol. 177, no. 10, pp. 7398-7405, 2006.

[19] F. Meloni, M. Morosini, N. Solari et al., "Foxp3 expressing $\mathrm{CD}^{+} \mathrm{CD}^{+} 5^{+}$and $\mathrm{CD}^{+} \mathrm{CD} 28^{-} \mathrm{T}$ regulatory cells in the peripheral blood of patients with lung cancer and pleural mesothelioma," Human Immunology, vol. 67, no. 1-2, pp. 112, 2006.

[20] B. Karagoz, O. Bilgi, M. Gümüs et al., " $\mathrm{CD} 8^{+} \mathrm{CD} 28^{-}$cells and $\mathrm{CD} 4{ }^{+} \mathrm{CD} 25^{+}$regulatory $\mathrm{T}$ cells in the peripheral blood of advanced stage lung cancer patients," Medical Oncology, vol. 27, no. 1, pp. 29-33, 2010.

[21] T. Sasada, M. Kimura, Y. Yoshida, M. Kanai, and A. Takabayashi, "CD4 ${ }^{+} \mathrm{CD} 25^{+}$regulatory $\mathrm{T}$ cells in patients with gastrointestinal malignancies: possible involvement of regulatory T cells in disease progression," Cancer, vol. 98, no. 5, pp. 10891099, 2003.

[22] C. B. Ambrosone, M. K. Nesline, and W. Davis, "Establishing a cancer center data bank and biorepository for multidisciplinary research," Cancer Epidemiology Biomarkers and Prevention, vol. 15, no. 9, pp. 1575-1577, 2006.

[23] J. Grant, K. Bourcier, S. Wallace et al., "Validated protocol for FoxP3 reveals increased expression in type 1 diabetes patients," Cytometry B, vol. 76, no. 2, pp. 69-78, 2009.

[24] S. Sakaguchi, T. Yamaguchi, T. Nomura, and M. Ono, "Regulatory T cells and immune tolerance," Cell, vol. 133, no. 5, pp. 775-787, 2008.
[25] I. Kryczek, R. Liu, G. Wang et al., "FOXP3 defines regulatory t cells in human tumor and autoimmune disease," Cancer Research, vol. 69, no. 9, pp. 3995-4000, 2009.

[26] A. M. Wolf, D. Wolf, M. Steurer, G. Gastl, E. Gunsilius, and B. Grubeck-Loebenstein, "Increase of regulatory T cells in the peripheral blood of cancer patients," Clinical Cancer Research, vol. 9, no. 2, pp. 606-612, 2003.

[27] S. Sakaguchi, N. Sakaguchi, M. Asano, M. Itoh, and M. Toda, "Immunologic self-tolerance maintained by activated $\mathrm{T}$ cells expressing IL- 2 receptor $\alpha$-chains (CD25): breakdown of a single mechanism of self- tolerance causes various autoimmune diseases," Journal of Immunology, vol. 155, no. 3, pp. 1151-1164, 1995.

[28] S. Sakaguchi, T. Takahashi, and Y. Nishizuka, "Study on cellular events in postthymectomy autoimmune oophoritis in mice. I. Requirements of Lyt-1 effector cells of oocytes damage after adoptive transfer," Journal of Experimental Medicine, vol. 156, no. 6, pp. 1565-1576, 1982.

[29] S. Sakaguchi, T. Takahashi, and Y. Nishizuka, "Study on cellular events in post-thymectomy autoimmune oophoritis in mice. II. Requirements of Lyt-1 cells in normal female mice for the prevention of oophoritis," Journal of Experimental Medicine, vol. 156, no. 6, pp. 1577-1586, 1982.

[30] R. Gregg, C. M. Smith, F. J. Clark et al., "The number of human peripheral blood $\mathrm{CD}^{+} \mathrm{CD} 25$ high regulatory $\mathrm{T}$ cells increases with age," Clinical and Experimental Immunology, vol. 140, no. 3, pp. 540-546, 2005.

[31] B. Barceló, J. Pons, J. M. Ferrer, J. Sauleda, A. Fuster, and A. G. N. Agustí, "Phenotypic characterisation of T-lymphocytes in COPD: abnormal $\mathrm{CD} 4{ }^{+} \mathrm{CD} 25^{+}$regulatory T-lymphocyte response to tobacco smoking," European Respiratory Journal, vol. 31, no. 3, pp. 555-562, 2008.

[32] C.-A. Brandsma, M. N. Hylkema, B. W. A. van der Strate et al., "Heme oxygenase-1 prevents smoke induced B-cell infiltrates: a role for regulatory T cells?" Respiratory Research, vol. 9, article 17, 2008.

[33] U. Costabel, K. J. Bross, and C. Reuter, "Alterations in immunoregulatory T-cell subsets in cigarette smokers. A phenotypic analysis of bronchoalveolar and blood lymphocytes," Chest, vol. 90, no. 1, pp. 39-44, 1986.

[34] R. Vassallo, K. Tamada, J. S. Lau, P. R. Kroening, and L. Chen, "Cigarette smoke extract suppresses human dendritic cell function leading to preferential induction of Th-2 priming," Journal of Immunology, vol. 175, no. 4, pp. 2684-2691, 2005.

[35] X. L. Yuan, L. Chen, M. X. Li et al., "Elevated expression of Foxp3 in tumor-infiltrating Treg cells suppresses T-cell proliferation and contributes to gastric cancer progression in a COX-2-dependent manner," Clinical Immunology, vol. 134, no. 3, pp. 277-288, 2010.

[36] K. Atarashi, T. Mori, R. Yoshiki, K. Kabashima, H. Kuma, and Y. Tokura, "Skin application of ketoprofen systemically suppresses contact hypersensitivity by inducing $\mathrm{CD} 4^{+} \mathrm{CD} 25^{+}$ regulatory T cells," Journal of Dermatological Science, vol. 53, no. 3, pp. 216-221, 2009.

[37] L. Arruvito, M. Sanz, A. H. Banham, and L. Fainboim, "Expansion of $\mathrm{CD}^{+}{ }^{+} \mathrm{CD} 25^{+}$and $\mathrm{FOXP}^{+}$regulatory $\mathrm{T}$ cells during the follicular phase of the menstrual cycle: implications for human reproduction," Journal of Immunology, vol. 178, no. 4, pp. 2572-2578, 2007.

[38] G. A. Prieto and Y. Rosenstein, "Oestradiol potentiates the suppressive function of human $\mathrm{CD} 4{ }^{+} \mathrm{CD} 25^{+}$regulatory T cells by promoting their proliferation," Immunology, vol. 118, no. 1, pp. 58-65, 2006. 
[39] J. Womack, P. C. Tien, J. Feldman et al., "Obesity and immune cell counts in women," Metabolism, vol. 56, no. 7, pp. 9981004, 2007.

[40] M. Zeyda, J. Huber, G. Prager, and T. M. Stulnig, "Inflammation correlates with markers of T-cell subsets including regulatory $\mathrm{T}$ cells in adipose tissue from obese patients," Obesity, vol. 19, no. 4, pp. 743-748, 2011.

[41] V. De Rosa, C. Procaccini, G. Calì et al., "A key role of leptin in the control of regulatory T cell proliferation," Immunity, vol. 26, no. 2, pp. 241-255, 2007.

[42] G. Matarese, C. Procaccini, V. De Rosa, T. L. Horvath, and A. La Cava, "Regulatory T cells in obesity: the leptin connection," Trends in Molecular Medicine, vol. 16, no. 6, pp. 247-256, 2010.

[43] E. Lahelma, P. Martikainen, M. Laaksonen, and A. Aittomäki, "Pathways between socioeconomic determinants of health," Journal of Epidemiology and Community Health, vol. 58, no. 4, pp. 327-332, 2004.

[44] E. Ammirati, D. Cianflone, M. Banfi et al., "Circulating $\mathrm{CD} 4{ }^{+} \mathrm{CD} 25$ hiCD127lo regulatory T-cell levels do not reflect the extent or severity of carotid and coronary atherosclerosis," Arteriosclerosis, Thrombosis, and Vascular Biology, vol. 30, no. 9, pp. 1832-1841, 2010. 


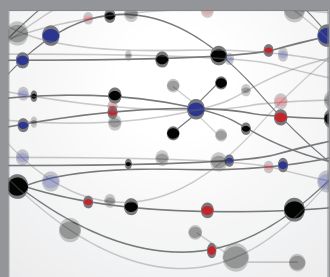

The Scientific World Journal
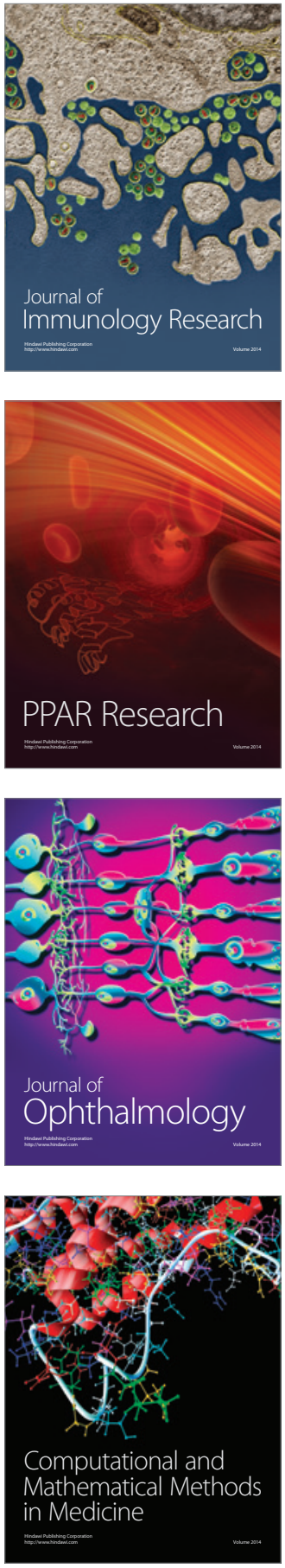

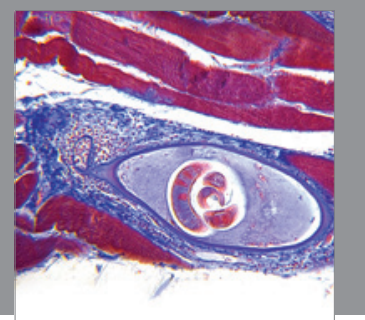

Gastroenterology

Research and Practice
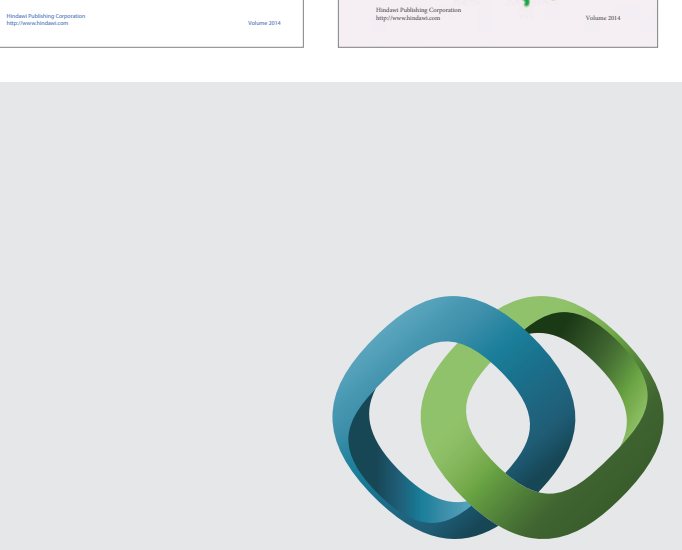

\section{Hindawi}

Submit your manuscripts at

http://www.hindawi.com
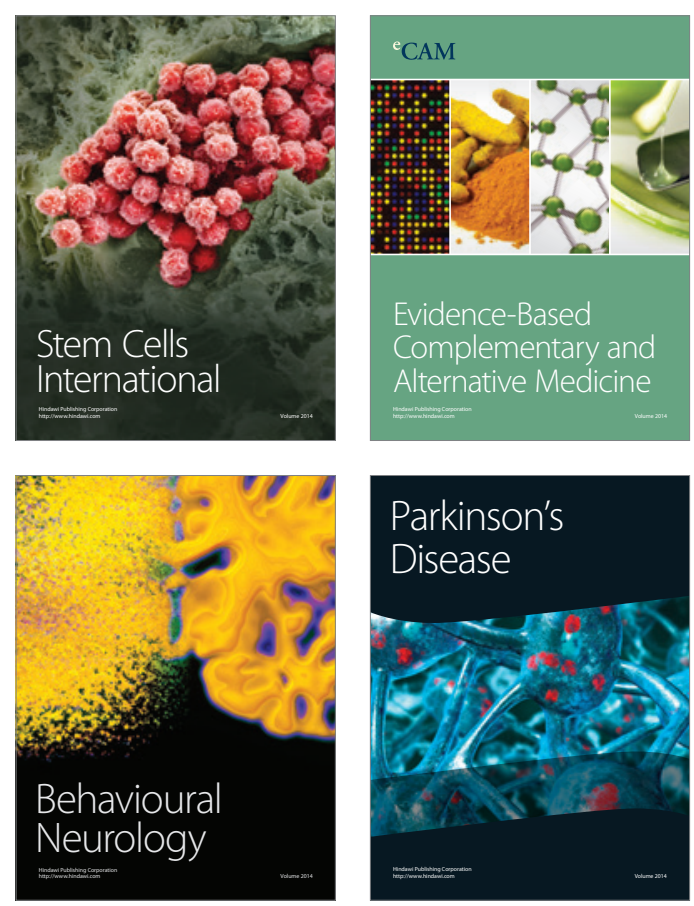

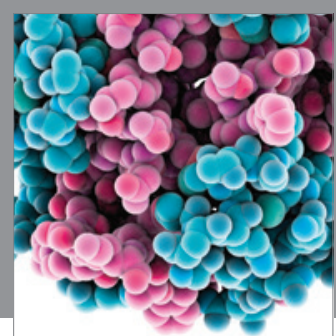

Journal of
Diabetes Research

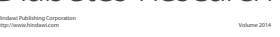

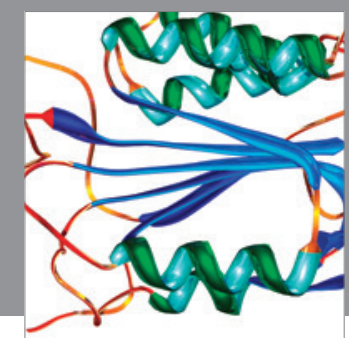

Disease Markers
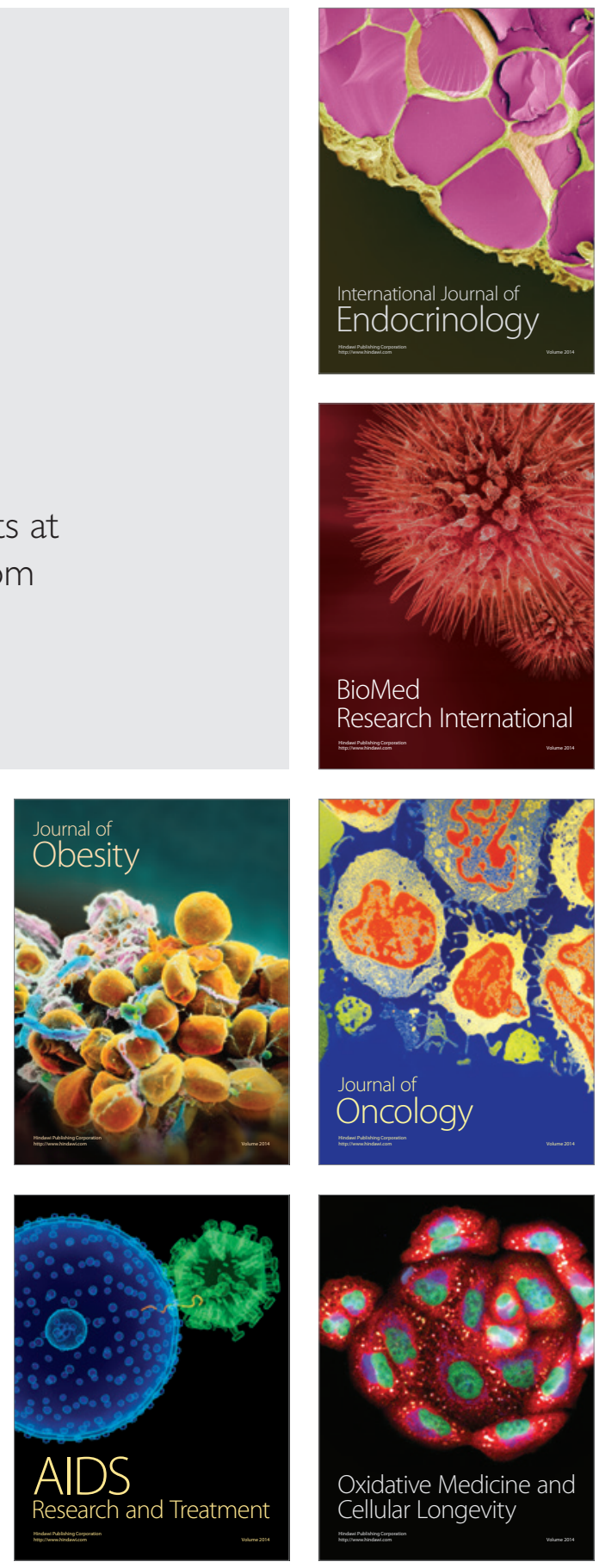